\title{
LA INSTITUCIONALIZACIÓN DEL OFICIO DE PEDAGOGIZAR LOS CUERPOS: EL NACIMIENTO DE LA FORMACIÓN PROFESIONAL EN EDUCACIÓN FÍSICA EN ARGENTINA (1897-1912)
}

\author{
Eduardo Lautaro Galak ${ }^{1}$
}

\section{RESUMEN}

Esta indagación aborda una problemática histórica cuyos efectos no dejan de ser actuales: las disputas por la legitimidad del oficio de la Educación Física. Se reflexiona sobre cómo se gestó esta práctica en Argentina y cómo la institucionalización de la profesionalización garantizó su reproducción. De allí que se estudien los discursos dominantes del pasaje del siglo XIX al XX y cómo de ellos resultaron dos posicionamientos epistémicos claramente definidos, uno de corte "militarista" y otro "cívico-pedagógico". Organizado en base a cinco acontecimientos cruciales en la institucionalización del oficio de la Educación Física que sucedieron entre 1898 y 1912, se analizan las voces contemporáneas de diferentes agentes ligados a la pedagogización de prácticas corporales en la Argentina.

Palabras clave: educación física, formación profesional, política, cuerpo, institucionalización.

\footnotetext{
${ }^{1}$ Consejo Nacional de Investigaciones Científicas y Técnicas (Conicet), Universidad Nacional de La Plata (UNLP)/Instituto de Investigaciones en Humanidades y Ciencias Sociales (IdIHCS), Buenos Aires, Argentina.
} 


\title{
A INSTITUCIONALIZAÇÃO DO OFICIO DE PEDAGOGIZAR OS CORPOS: O NASCIMENTO DA FORMAÇÃO PROFISSIONAL DE EDUCAÇÃO FÍSICA NA ARGENTINA (1897-1912)
}

\begin{abstract}
RESUMO
Este artigo aborda uma problemática histórica cujos efeitos são ainda atuais: as disputas sobre a legitimidade do oficio da Educação Física. Reflete-se sobre como essa prática foi desenvolvida na Argentina e como a institucionalização da profissionalização garantiu sua reprodução. Estudouse os discursos dominantes da passagem do século XIX ao XX dos quais resultaram em duas posições epistêmicas claramente definidas, uma de estilo "militarista" e a outra "cívicopedagógica". Tendo como base cinco processos importantes da institucionalização do oficio de Educação Física ocorridos entre 1898 e 1912, neste texto analisam-se as vozes contemporâneas de diferentes agentes relacionados à pedagogia das práticas corporais na Argentina no momento em tela.
\end{abstract}

Palavras-chave: educação física, formação profissional, política, corpo, institucionalização.

\section{THE INSTITUTIONALIZATION OF THE CORPORAL PEDAGOGY PROFESSION: THE BIRTH OF CERTIFIED TEACHERS OF PHYSICAL EDUCATION IN ARGENTINA (1897-1912)}

\begin{abstract}
This research analyzes a historical problem which results are still effectives: the disputes over the legitimacy of the profession of Physical Education. The intention is to think how this practice was conceived and how it institutionalization guaranteed its reproduction. For that, dominant discourses of the passage from the 19th to the 20th century are studied, and how from that resulted two clearly defined epistemic positions, one "militaristic" and the other "civicpedagogical". Organized on the basis of five crucial events that took place between 1898 and 1912 about the institutionalization of the professionalization of Physical Education, it is analyze the contemporary voices of different agents linked to the pedagogization of corporal practices in Argentina.
\end{abstract}

Keywords: physical education, professionalization, politics, body, institutionalization. 


\section{L'INSTITUTIONNALISATION DU MÉTIER DE LA PÉDAGOGIE DU CORPS: LA NAISSANCE DE LA FORMATION PROFESSIONNELLE EN ÉDUCATION PHYSIQUE EN ARGENTINE (1897-1912)}

\section{RÉSUMÉ}

Cette analyse aborde un problème historique dont les effets se ressentent encore aujourd'hui: les conflits sur la légitimité du métier de l'éducation physique. Le but est de retracer la manière dont ces pratiques se développent en Argentine et comment l'institutionnalisation de la profession a garanti sa reproduction. Les discours dominants du tournant des XIXe et XXe siècles sont étudiés et nous verrons comment cela a abouti à deux positions épistémiques clairement définies, l'une militaire et l'autre civique-pédagogique. Organisé sur la base de cinq événements cruciaux qui ont eu lieu entre 1898 et 1912, autour de la professionnalisation de l'éducation physique, cet article analyse les voix contemporaines de différents agents liés à la pédagogie des pratiques corporelles en Argentine.

Mots-clés: education physique, formation professionnelle, politique, corps, institutionnalisation. 


\section{INTRODUCCIÓN}

Con el ejercicio físico, ó, más bien dicho, con los diversos sistemas o métodos preconizados para su enseñanza, ocurre lo que con las diversas creencias religiosas: cada cual cree que fuera de la suya no hay salvación (POURTEAU, 1897, p. 75).

La crónica del nacimiento de la Educación Física muestra que los sucesos que configuraron los dos principales establecimientos encargados de la formación superior de la disciplina, la Escuela de Gimnasia y Esgrima del ejército (en adelante "Escuela") y el Instituto Superior Nacional de Educación Física ("Instituto"), constituyen también las génesis de las disputas simbólicas que posibilitaron la fundación y fundamentación del campo de su profesionalización en Argentina.

La tarea de este escrito consiste entonces en inquirir los hitos ocurridos durante la primera década del siglo XX, hechos que establecieron, como consecuencia, los procesos por los cuales se construyeron las narrativas, las taxonomías y las retóricas que estas instituciones configuraron. Las cuales devinieron, una vez sistematizados y reproducidos, en dos discursos relativamente autónomos respecto al otro y relativamente homogéneos en su interior que conforman dos doctrinas que pueden ser categorizadas como "militarista” y “cívico-pedagógica”.

Mediante una metodología histórica-hermenéutica que procure comprender los procesos disciplinares como efectos de un contexto que los interpela, ${ }^{2}$ se analizan una serie de cinco acontecimientos que resumen la historia de la institucionalización del oficio: la colocación de la piedra fundamental de la Escuela en 1897, la denominación oficial de "Educación Física” en 1903, la

\footnotetext{
2 Partiendo de reconocer la escasa cantidad de estudios en Argentina sobre formación profesional en Educación Física antes de mediados de siglo XX, entre los que se destacan las investigaciones desarrolladas por Jorge Saraví Riviere (1985; 1998), Ángela Aisenstein (2006) y Pablo Scharagrodsky (2011; 2014), este trabajo retoma el corpus teórico e historiográfico utilizado en Galak (2012a).
} 
instauración de los primeros Cursos para maestros que complementan el oficio en la materia entre 1901 y 1906, la conformación del Instituto en 1912 y la autorización, hacia finales del período analizado, a egresados militares para que dicten clases en la educación pública.

\section{LA ESCUELA DE GIMNASIA Y ESGRIMA COMO PRIMERA INSTITUCIONALIZACIÓN DE LA FORMACIÓN EN EDUCACIÓN FÍSICA}

En el contexto de la masiva, constante y creciente inmigración ocurrida durante el siglo XIX, propiciada por la consigna de Juan Bautista Alberdi de que "gobernar es poblar", se produjo el arribo de un grupo de maestros de esgrima, en su gran mayoría provenientes de la Escuela Magistral de Roma (conocida como "La Farnesina"): entre otros, Eugenio Pini, Víctor Ponzoni, Escipión Ferretto, André Mari, José Scanzi y Juan Bay (padre). Estos especialistas en el manejo de las armas colaboraron en la conformación en 1897 de lo que por entonces se llamó Escuela Militar de Esgrima, cuya creación fue encomendada por el entonces Senador Nacional Carlos Pellegrini, recayendo su dirección en Pini y la vice-dirección en Ponzoni. De esa manera, se coloca la piedra fundamental sobre la que se erige la posteriormente denominada Escuela de Gimnasia y Esgrima, institución castrense que funcionó hasta 1903, momento en el que cierra sus puertas aduciendo cubrir todos los cargos que el ejército precisaba hasta ese entonces. A partir de allí, y hasta su reapertura en 1924, operó intermitentemente y de diversas maneras según lo requería la demanda de profesionales: modificando tanto su nombre - desde Escuela Militar de Esgrima a Escuela Militar de Gimnasia y Esgrima, para luego pasar a denominarse Escuela de Gimnasia y Esgrima -, su titulación - primero otorgó diploma de Maestro de Esgrima, posteriormente de Maestro Militar de Gimnasia y Esgrima y finalmente el de Maestro de Gimnasia y Esgrima -, como en su modalidad de cursada variando la cantidad de años y sus diseños curriculares - (COMANDO EN JEFE 
DEL EJÉRCITO, 1971, p. 303-305).

El suceso que implicó esta nueva institución, primera en su tipo en Argentina y pionera en Latinoamérica, se basó fundamentalmente en la conjunción de dos procesos paralelos: por un lado, es producto de la organización de los Estados modernos, de la importación de modelos gimnásticos europeos de segunda mitad de siglo XIX y de la diseminación de la "gimnasia militar argentina" a raíz de la obligatoriedad de los servicios militares (GALAK, 2012a); y, por el otro, es resultado de la participación activa de una serie de actores e instituciones provenientes de las elites porteñas que vieron representados sus ideales en las prácticas que se realizaban en la Escuela (SCHARAGRODSKY, 2011, p. 446-448). La inclusión en 1901 de la gimnasia como uno de sus ejes fundamentales marcó un punto de inflexión en la formación de profesionales de enseñanza de actividades físicas en la Argentina: justificada por "la alta utilidad de incorporar a su programa la enseñanza de la gimnasia, la que en tan elevado grado aumenta las aptitudes físicas y las cualidades militares del soldado" (ARGENTINA, 19 abr. 1901), a partir de allí se cambió de nombre de la institución para pasar a denominarse Escuela Militar de Gimnasia y Esgrima.

Una primera cuestión que caracteriza a la Escuela son los contenidos que conforman los primeros currículum de gimnasia y la manera en que se los ordenan: la elección de cuáles elementos curriculares componen el Plan de Estudios demuestra, por un lado, la inseparable filiación con la corporación militar y, por el otro, la fundamentación médico-higienista con que se justifica la pedagogía de la Escuela - con materias como Anatomía y Fisiología e Higiene y agrega Gimnasia Teórica Aplicada a la Mecánica Humana, Ventajas de los pequeños aparatos sobre los grandes aparatos, Pedagogía e Historia de la Gimnasia y Esgrima (ARGENTINA, 1900, p. 131-132) -. Además de formarse en los preceptos de una gimnasia "racional" que contemple la salud de la raza, caracteriza a este establecimiento que su Plan de Estudios se complementa con la instrucción de las prácticas de tiro y de esgrima. Esto es, destina gran parte de su curriculum a educar en el uso de las armas, con el objetivo de reforzar la 
preparación para la defensa nacional y afianzar así el ideario patriótico y nacionalista que motiva el ejército.

Como segunda particularidad puede destacarse la reproducción de la corriente gimnástica italiana por parte de los docentes emigrados de aquél país, justificando sus prácticas fundamentalmente por los aportes de la teoría de Emilio Baumann (SCHARAGRODSKY, 2005, p. 51), aunque secundariamente pueden sumarse los de Rodolfo Obermann (SARAVÍ RIVIERE, 1998, p. 9). Esto es, la Escuela transmitía contenidos basados en una conjunción de las gimnásticas alemana e italiana, asociación de dos doctrinas disímiles pero que en el caso de este establecimiento convivieron gracias a la importación de las ideas de Obermann, quien, expatriado de su Suiza natal, llevó a Italia el Turnen o Método Gimnástico alemán. Contra esta postura de sumisión de los ejercicios gimnásticos a otros intereses, Baumann se distancia de su maestro Obermann al establecer que los ejercicios físicos no tienen que justificarse por criterios militares, sino que deben sustentarse en bases racionales y científicas, de acuerdo con las propuestas pedagógicas académicas que desde la Universidad de Turín postula Ángelo Mosso. Por su parte, en tanto reformador de las tradicionales ideas gimnásticas, Mosso plantea dejar atrás las actividades "artificiales” y enseñar ejercitaciones corporales naturales, compuestas por juegos al aire libre y por una gimnasia fisiológica y racional.

En síntesis, la gimnasia que la Escuela reproducía surge de la interpretación local de estas dos corrientes italianas en disputa: la bolognesa, cuyo principal exponente fue Baumann, ligada a la enseñanza de ejercitaciones corporales basadas en conocimientos científicos, fisiológicos e higiénicos; y la turinesa, de características principalmente militares, que de la mano de Obermann diseminó una práctica que reúne aspectos del Turnen alemán y del idealismo nacionalista italiano con la utilización de aparatos pequeños y grandes.

Además del curriculum de instrucción física, la educación moral que la Escuela despliega converge con los principios que las elites porteñas transmiten en los clubes metropolitanos a finales del siglo XIX: los ideales de buena cultura, 
el pulimento de los modales, la corrección en las maneras y la formación del carácter como sostienen Sandra Gayol y Marta Madero (2007, p. 225-226), pero también la búsqueda del honor y la caballerosidad, a lo que puede agregarse el gusto por la estética del movimiento ejecutado de modo preciso. Todo lo cual, como puede interpretarse, generó que opere en la Escuela una matriz de distinción. Dicho de otro modo: si bien este establecimiento nace como respuesta a la falta de personal idóneo que enseñara ejercicios físicos, esta confluencia de moralidades genera que en sus orígenes sea una institución cerrada y endogámica.

A pesar de haber comenzado como una institución instructora exclusivamente de personal castrense, dos hechos marcaron la Escuela como importante difusora de la cultura física en Argentina: primero, cuando abre sus puertas a la comunidad civil en 1901, enseñando su doctrina a todo aquel que así lo pretendiera - aunque con prioridad para el personal militar - (ARGENTINA, 19/04/1901), y, segundo, cuando en 1909 por Decreto del Poder Ejecutivo se autoriza a todos los egresados de la Escuela a dictar clases en el Sistema Educativo formal (CRISTIANI, 1967, p. 51-52). Ambos hechos, junto con la aparición también en 1901 de la Educación Física "civil" como un otro con quien dialogar, provocaron hacia finales de la primera década del siglo XX un movimiento que pretende instalar prácticas castrenses en la educación estatal. Pero eso pertenece a otra historia.

\section{LA CARTA DE PIZZURNO PARA CONFIGURAR EL OFICIO DESDE EL ÁMBITO OFICIAL-CIVIL}

El 21 de septiembre de 1901, el por entonces Inspector General de Enseñanza Secundaria y Normal, Pablo Pizzurno, le escribe al Ministro de Justicia e Instrucción Pública, Juan Eugenio Serú, para presentarle un proyecto de capacitación docente para la enseñanza de actividades corporales, con el explícito objetivo de "formar en breve tiempo maestros de ejercicios físicos, con 
la preparación teórica y las aptitudes prácticas requeribles para dirigir con acierto el desenvolvimiento físico de nuestros niños y jóvenes de uno y otro sexo" (ARGENTINA, 9 oct. 1901). En este claro intento por profesionalizar el área, Pizzurno (1902, p. 89-90) realiza una radiografía de la situación, arguyendo que

\begin{abstract}
no hay entre nosotros maestros que reúnan esas condiciones; y no los hay, porque la enseñanza de la gimnasia ha estado a cargo de especialistas, o titulados especialistas casi siempre extranjeros y de la antigua escuela, o de militares, desprovistos unos y otros, del concepto a lo que el ejercicio físico debe pedirse para los niños y para los jóvenes [...], careciendo de ese concepto, sin las nociones teóricas científicas indispensables, sin el conocimiento práctico, empírico siquiera, de los ejercicios y juegos más útiles y sin aptitudes pedagógicas, tan indispensables para dirigir la educación física (PIZZURNO apud ARGENTINA, 9 oct. 1901).
\end{abstract}

Para suplir esta situación de que las lecciones de "gimnasia", tal como las definía, eran "aburridas y antipáticas", propone crear "un curso complementario de vacaciones y cuyo objeto principal es permitir que sin pérdida de tiempo los profesores y maestros que actualmente tienen a su cargo la educación física de nuestros escolares y colegiales, puedan ponerse en condiciones de cumplir debidamente su misión” (ARGENTINA, 9 oct. 1901).

En principio, dos cuestiones caben remarcarse que se manifiestan con particular elocuencia en la carta de Pizzurno: por un lado, la mención a ese otro conjunto de instructores en actividades físicas, que proviene del ámbito castrense y que enseñan ejercicios militares básicos, y, por el otro, la insistencia de justificar esta práctica pedagógica mediante criterios científicos que persigan la producción de efectos fisiológicos e higiénicos. Argumento que se produce en el marco de un "cambio de episteme", como afirma Pablo Scharagrodsky (2011, p. 442), que sucedió en esta época y que legitimó la enseñanza de actividades físicas en el contexto escolar.

Como análisis cruzado de ambas cuestiones puede señalarse que tanto la postura "militarista" como la de Pizzurno buscan criterios de verdad en la ciencia, 
aunque de maneras disímiles: si bien los proyectos teóricos utilizados para justificar las prácticas son similares - fundamentalmente médicos e higienistas -, su interpretación varía según el caso. La distinción puede hallarse en la búsqueda de Pizzurno primero y de su continuador Enrique Romero Brest después, de imprimirle además principios pedagógicos. Esto es, volverla escolar, generando a su vez literatura científico-educativa específica.

Puede observarse también en las palabras de Pizzurno una reflexión crítica acerca del curriculum de la época, entendiendo que la decisión de si optar por ejercicios artificiales o naturales, si utilizar elementos en las clases o si justificar las prácticas con criterios marciales, no puede recaer en la mera elección del maestro, sino que deben definirse extemporáneamente por instancias oficiales cuáles deben ser los contenidos, y sistematizarse las razones que avalen sus métodos. De esta manera, este hecho resulta un hito fundante, ya que promueve por primera vez la definición no sólo de los saberes de la materia, sino también cómo deben enseñarse de un modo "profesional".

Cabe destacar que este discurso que Pizzurno redacta en septiembre de 1901 sirve de antecedente inmediato para la conformación de los primeros cursos de formación de la disciplina fuera del ámbito militar: dos semanas más tarde, el 8 de octubre, se crea por decreto el Curso teórico-práctico de ejercicios físicos, que se replica anualmente hasta 1906 de distintas maneras y con nombres diferentes. Tres décadas después Romero Brest afirmaba que ello no sólo permitió la reorganización de la Educación Física en un sentido más racional que militar, sino que tuvo como consecuencias la creación del "Sistema Argentino de Educación Física” como método oficial y la profesionalización de la disciplina, pues "exigía necesariamente la preparación de los profesores, capacitados práctica y doctrinariamente para realizarla" (1938, p. 52). Entre los objetivos que persigue esta práctica se incluye el fomento de la salud del individuo, el mantenimiento del equilibrio entre las funciones vitales, favorecer el desarrollo de las aptitudes, de los hábitos, y de las habilidades físicas cotidianas: una "desintoxicación del organismo y social para la alegría de vivir" (ARGENTINA, 9 
oct. 1901).

Por último, la carta continúa dejando como legado la búsqueda de la profesionalización de la práctica, al afirmar que, para que se vean beneficiados los niños y jóvenes de la educación física,

[...] importa preparar gran número de maestros: pero, una vez por todas, bien preparados y preparados para nosotros, es decir, que no sólo conozcan lo necesario anatomía, fisiología e higiene, y cuales son los ejercicios que convienen a los niños según sus edades y condiciones y, en ciertos casos, hasta según los lugares, sino también cómo organizarlos en las escuelas nuestras, dentro de las por ahora insalvables deficiencias de nuestros locales, horarios, etc. para sacar de aquellos, los ejercicios todo el provecho posible (PIZZURNO, 1902, p. 91).

En la búsqueda de Pizzurno por la profesionalización de la materia se observa, como constitutiva, la distinción con otras formas tanto de concebir la disciplina cuanto de cómo debía ser enseñada. Nuevamente puede notarse en su discurso que el estar "bien preparados para nosotros", "para nuestras escuelas" implica la existencia de un otro distinto, principalmente representado por aquellos educadores que proponían instruir ejercicios militares o "artificiales". Esta nueva corriente en el campo de la cultura física comienza a cuestionar la enseñanza de la "gimnasia militar argentina" y propone, en nombre de la ciencia médica y del higienismo reinante, dos prácticas consideradas modernas: los juegos y los ejercicios físicos racionales.

Si bien las palabras de Pizzurno configuraron claramente una empresa política, pueden encontrarse contradicciones en su "cómo": al mismo tiempo que enuncia su pretensión de profesionalizar el área con docentes específicos, expresa que "nadie más indicado que un médico, especialista teórico y práctico a la vez, que reúna a la competencia la dosis de fe y de entusiasmo necesarios para asegurar los resultados" (ARGENTINA, 9 oct. 1901). Precisamente, como una suerte de legado simbólico, Pizzurno se refirió al momento en el cual Romero Brest se recibió de médico de la siguiente manera: 
quédese, le dije, al servicio de la enseñanza. Al país no le es indispensable un médico más por notable que pueda llegar a ser. Ud. será infinitamente más útil y salvará mayor número de vidas previniendo la enfermedad, difundiendo la salud con todas sus benéficas consecuencias, por medio de una educación física racional impartida de un extremo al otro de la Republica. Ud. debe ser el hombre de la educación física en el país, aún cuando ello le cueste sacrificios de orden material. No solo de pan vive el hombre. Recuérdelo. Y el joven médico, cuyos sentimientos altruistas ya conocía, se dejo, fácilmente sugestionar (PIZZURNO, 1914, p. 403).

En definitiva, lo que la carta de Pizzurno pone de manifiesto es la necesidad de un oficio - aún con incertezas -, inaugurando la búsqueda para que esa maestría se produzca en la construcción de una práctica que sea sistemática, homogénea, recurrente, general y, fundamentalmente, específica. Cuestión que se materializa con los Cursos teórico-prácticos para el área y con la obra de su sucesor político en la disciplina: aquél médico, "el hombre de la educación física en el país”, el Dr. Enrique Romero Brest.

\section{LOS CURSOS TEMPORARIOS DE 1901, EL NACIMIENTO DE LA EDUCACIÓN FÍSICA EN 1903 Y LA CREACIÓN DE LOS CURSOS NORMALES}

En el marco de este proceso en el que se origina la voluntad política tanto de profesionalizar la actividad docente como de sistematizar las prácticas que componen el currículum de la disciplina, se produce también el nacimiento stricto sensu de la Educación Física: afirmación que se sostiene en la carta que le escribe Enrique Romero Brest al Ministro de Justicia e Instrucción Pública Juan Ramón Fernández, el 9 de marzo de 1903, en la que le solicita que todas aquellas actividades o ejercicios físicos escolares sean denominadas curricularmente como "Educación Física”. 


\begin{abstract}
solo me resta pedir al señor Ministro me permita proponer que en el programa de las Escuelas Normales figure esta materia con el nombre de 'Educación física', nombre más apropiado á la clase de estudios que comporta en estas Escuelas. Se trata en ellas de algo más que los simples Ejercicios físicos, desde el momento en que no solo se actúa sobre el individuo como organismo físico sinó también como ser psíquico y moral y pues que se emprenden estudios extendidos de fisiología e higiene, lo que comprende algo más que la simple expresión 'Ejercicios físicos' (ROMERO BREST, 1903, p. 87-88).
\end{abstract}

Este hito, que significa el pasaje de la educación física a la Educación Física, ${ }^{3}$ pone a su vez de manifiesto el estado de la situación laboral del área, con una mayor demanda antes que una oferta de profesionales, quienes reproducían lo que Romero Brest (1903, p. 5-6) denominaba como "gimnasia puramente teórica” o "empírica”. Es decir, enseñaban un conjunto de ejercitaciones físicas sin órdenes preestablecidos, sin planificaciones sistemáticas ni ideas consensuadas que sustentaran esas prácticas.

Esta correspondencia se produce en un contexto particular y significativo en la historia de la construcción de la profesionalidad en la disciplina en Argentina: la puesta en práctica de los Cursos teórico-prácticos de ejercicios físicos, que se realizaron desde 1901 hasta 1906, con carácter de temporarios. Estos cursos continuaron reproduciendo dos cuestiones relacionadas: por un lado, se replicaba el sentido integralista con que nace la educación física, ya que se la establece como complemento de lo moral y lo intelectual (GALAK, 2013), y, por el otro, tanto en los contenidos como en su evaluación puede observarse que las búsquedas pasan por construir un posicionamiento sobre "qué es ser profesor en Educación Física” que se distinga de la opuesta propuesta de la Escuela del ejército.

\footnotetext{
3 En una suerte de pasaje de un sintagma a un oxímoron (GALAK, 2012b), se distingue educación física con minúsculas de Educación Física con mayúsculas, entendiendo que la primera constituye una manera de nombrar acciones educativas, sean pedagógicas o no, que conllevan una utilización manual o corporal; en tanto que por la segunda expresión se comprenden aquellas prácticas que sistemáticamente hayan sido institucionalizadas bajo la denominación "Educación Física". Esto es, mientras que la primera manifiesta todas las formas escolares de educar el cuerpo, la segunda remite sólo a las prácticas de la pedagogía institucional del cuerpo por excelencia.
} 
Así, pueden contraponerse al disciplinamiento de los ejercicios gimnásticos sistemáticos y de las prácticas de tiro y esgrima que sustentaban los miembros de la Escuela, el interés por la pedagogía, la psicología, el canto o los juegos libres de quienes pensaron estos Cursos. En otras palabras, si el leitmotiv del establecimiento castrense era adiestrar al músculo y a la máquina humana para educar al ciudadano, el de Pizzurno y Romero Brest, basado en esa inseparable relación entre pensamiento y movimiento y en ese estrecho vínculo entre los conocimientos psicológicos y los fisiológicos que implican su "educación física racional", postula instruir al físico para ilustrar también al hombre, su intelecto y su psiquis (ROMERO BREST, 1903, p. 83-84).

Esto conduce particularmente al quid del presente apartado: del seno de esa conjunción de procesos, entre el reclamo por establecer el nombre "Educación Física" y la inauguración de los Cursos que reproduzcan esas primeras maneras de entender la disciplina, surge un modo particular de desarrollarla, un modelo que Romero Brest denomina "Sistema Argentino de Educación Física", y que consiste en un proyecto nacional que se establece durante el primer tercio del siglo XX como el método oficial transmitido por los profesionales de la disciplina (AISENSTEIN; SCHARAGRODSKY, 2006, p. 161).

En 1905, en "Pedagogía de la Educación Física" - publicación que sienta las bases teóricas de los primeros Cursos -, Romero Brest define como objeto de la disciplina al "perfeccionamiento funcional", aunque con una particularidad distintiva: si bien el sentido histórico tradicional remite a la pretensión de variar las funciones biológicas producto de las ejercitaciones, y si bien ello se ajusta a la ley de la fisiología que define que "la función hace al órgano y determina sus variaciones" (1933, p. 6), establece que no debe reducirse su problema a la búsqueda de cambios orgánicos o al aumento económico de las fuerzas, sino más bien debe concebirse una "educación física racional y metódica" que incluya "al cerebro y al pensamiento" como partes de su objeto, pues "el verdadero concepto fisiológico del perfeccionamiento físico se encierra, entonces, en esta idea: la armonía completa y el funcionamiento pleno" (1933, p. 8). Gradual, científico, 
metódico, de inspiración positivista - adquiriendo ribetes espiritualistas con el correr del tiempo -,4 el "Sistema Argentino" se establece principalmente como un modelo educativo, como principios pedagógicos que guíen las acciones de una disciplina que a comienzos del siglo XX tenía por principal función "formar la identidad nacional a partir de procurar el perfeccionamiento de la raza" (1933, p. 156).

Respecto a la profesionalización de la disciplina, el "Sistema Argentino" procura que los docentes de Educación Física sean "verdaderos educadores y no solamente simples cultores aficionados del arte gimnástico" (ROMERO BREST, 1933, p. 158): "la intervención del maestro es entonces más para las direcciones, para dosar [sic] la cantidad, para evitar accidentes y para dirigir los perfeccionamientos" (1933, p. 73). Esto es, respecto a la didáctica, los docentes que se desempeñen en el marco del "Sistema Argentino" deben desarrollar las clases de ejercicios físico de manera completa, graduada, interesante, simultánea y disciplinada - sin confundir, "sin embrago, la disciplina exigida con la militar" (1933, p. 189-19o) -. En ese sentido, cabe explicitar que el método didáctico que propugnaban desde el Instituto era el "comando directo", por sobre el de "imitación" o el de "las series", debido a que lo encuentra "más completo fisiológica, pedagógica y psicológicamente” (1933, p. 256); cuestión que distingue, una vez más, este establecimiento con la Escuela, pues la corporación militarista proponía que los alumnos copien los pasos que el maestro-guíaejemplo indique.

Ahora bien, ¿en qué teorías sustenta Romero Brest el "Sistema Argentino"? Puede afirmarse que consiste en una interpretación local ecléctica de los principales aportes médicos, higienistas, pedagógicos y psicológicos que utilizan las gimnásticas sueca, francesa, inglesa y alemana - fundamentalmente de los más significativos postulados de los franceses Demeny, Arnould, Tissié,

\footnotetext{
4 Dice Saraví Riviere (1998, p. 62) que "este sistema era de inspiración positivista, pero llega a introducir la línea espiritualista en educación física. Tenía además una tendencia nacionalista”. De hecho, en varios de sus textos Romero Brest enuncia que la disciplina se apoya en cuatro "ideas": la anatómica, la fisiológica, la psicológica y la espiritual.
} 
Labit, Polin, Bouchard, Lagrange, Riant, Marey, Buisson; del italiano Mosso y del británico Spencer - (AGÜERO et al., 2009; AISENSTEIN; SCHARAGRODSKY, 2006; PIZZURNO, 1914; ROMERO BREST, 1903; GALAK, 2013). Sin embargo, Romero Brest realiza una serie de críticas a estas corrientes gimnásticas: a la francesa fundamentalmente por ser "anti-fisiológica", por tener orígenes castrenses y por tener fines "aristocráticos"; a la inglesa, aún alabando su carácter de juegos deportivos al aire libre y su componente esencial de emotividad, por transmitir inconvenientes de orden fisiológico; a la alemana por "su carácter de fuerza y militar que no ha perdido del todo desde su origen" (1903, p. 57); en tanto a la sueca, si bien la elogia por pretender ser "una gimnasia científica, basada en absoluto en las reglas fisiológicas y en las condiciones anatómicas del hombre en sus diversas edades" (1933, p. 353), esencialmente higiénica y no atlética, democrática y ortopédica, y aún coincidiendo con su currículum - compuesta principalmente por ejercicios metodizados graduados, y complementada por juegos, deportes y la natación -, la juzga insuficiente psicológicamente "porque descuida casi por completo la emotividad de la acción conjunta o solidaria, que motiva el deporte o el simple juego gimnástico" (1933, p. 355) y deficiente por su "metodismo riguroso que exige personal especial, condiciones locales apropiadas y talvez condiciones de raza que no tenemos nosotros".

He tratado así de estudiar un sistema ecléctico que basado en la mecánica y fisiología del organismo humano respondiera al mismo tiempo á las exigencias de nuestros locales y de nuestro personal enseñante (ROMERO BREST, 1903, p. 57).

En definitiva, para Romero Brest estos Cursos significaron una apuesta política, la oportunidad de establecer, primero, una manera de denominar la disciplina, y, segundo, un sistema moderno, racional, metódico y científico que conjugase criterios pedagógicos y discursos higienistas. En paralelo a la historia de la Escuela, se produjo esta contrapropuesta surgida del seno del movimiento pedagógico de la época: con el correr de los primeros años del siglo XX, el 
"Sistema Argentino de Educación Física" resulta triunfante, logrando imponer como gimnasia oficial, para los Sistemas Educativos nacionales, las gimnasias naturales fisiológicas-pedagógicas antes que las militares y de aparatos.

\section{EL PLAN DE ENSEÑANZA Y EDUCACIÓN FÍSICA NACIONAL, LOS CURSOS NORMALES Y LA APERTURA DEL INSTITUTO}

El 17 de febrero de 1905 se produce un acontecimiento que marca la historia de la formación de profesores en Educación Física en la Argentina: mediante el Decreto firmado por el Presidente Manuel Quintana y el Ministro de Justicia e Instrucción Pública Joaquín Víctor González, se establece el Plan de Enseñanza y Educación Física Nacional. Con esta ley se configuran no sólo los contenidos y la manera en que debe llevarse a cabo su enseñanza en los niveles primario, medio y especial, sino también el modo en que tienen que instruirse los futuros profesionales. En otras palabras, marca el rumbo hacia la institucionalización oficial definitiva de la disciplina, lo cual implica, además de decidir qué contenidos enseñar, la formulación de su Plan de Estudios. Es decir, un planteo sistemático, progresivo, pedagógico y didáctico de cómo enseñar los conocimientos, sus correlatividades y las duraciones de cada asignatura; cuestiones que se plasman en los Cursos Normales dictados desde 1906 y, posteriormente en 1912, con la inauguración del Instituto Nacional Superior de Educación Física.

Mediante este Plan el Poder Ejecutivo decreta la obligatoriedad de la Educación Física para todos los establecimientos argentinos de enseñanza primaria, secundaria, normal y especial, a partir de las siguientes consideraciones: a) que se vienen sosteniendo desde los Cursos temporarios de 1901 "progresos pedagógicos" en la formación de profesores, b) que hasta entonces existía una escasez del tiempo destinado a la educación física ocupado casi en su totalidad por las materias "teóricas, científicas o literarias, que no 
dejaban espacios para la experiencias, ejercitaciones y cultura física de la infancia y juventud", c) que había una "falta de unidad y correlación" que "sólo podía suprimirse haciendo extensiva la enseñanza de la educación física racional y metódica" a todos los niveles educativos, d) que su política debía ser nacional, su financiamiento estatal y su carácter oficial, e) que la enseñanza de la cultura física podía promover la educación moral a través de fomentar la sociabilidad, favorecer la solidaridad, la competencia sana y el esfuerzo noble, y f) que la Educación Física "es una forma de aplicación de la ciencia de la higiene". A su vez, fija como sus objetivos el "desarrollo armónico del organismo", el "acrecentamiento de la salud", la "formación del carácter del hombre y del ciudadano", el "cultivo de la belleza plástica y de la fuerza muscular", y el "perfeccionamiento de las aptitudes prácticas, especialmente aquellas militares que sean compatibles con los propósitos de la escuela" (ARGENTINA, 24 feb. 1905).

Tal como enuncia el Plan, se utilizaron como lineamientos básicos las recomendaciones realizadas por Romero Brest. Ello puede verse explícitamente en la continuidad entre ambos discursos, por ejemplo, en la elección de los principales contenidos que componen sus currícula (ejercicios metodizados al aire libre, excursiones escolares y juegos gimnásticos y sport). Sin embargo, hay un claro punto de discontinuidad: la vinculación de la disciplina con la corporación militar, pues la introducción de la enseñanza del tiro en las escuelas responde al ideario que sostenían desde la Escuela, y que lograron imponer en el Plan de 1905. Tal como establece el Decreto, la intención oficial pretendía que la Educación Física sirva también para la "formación de la fuerza militar del país y del espíritu de disciplina general en todos los órdenes, que serán en el porvenir una firme base para la consolidación definitiva de las instituciones y de la paz pública” (ARGENTINA, 24 feb. 1905).

Respecto a la profesionalización de la disciplina, punto central del Plan de 1905, se instituye que "la dirección de las clases de ejercicios físicos se hallará en cada establecimiento a cargo de un profesor, asistido de los auxiliares 
necesarios, a razón de un auxiliar por cada 80 alumnos”. Además, legisla los objetivos de los Cursos Normales de Educación Física en reemplazo de los cursos temporarios: desarrollándose en la Capital Federal, tendrán una duración de dos años y sus clases serán de carácter "experimental y científico".

En cuanto a la titulación, al concluir el primer año los alumnos reciben un "Certificado de Aptitud" para la enseñanza de ejercicios físicos que los habilita a ocupar puestos de auxiliares docentes, y al finalizar los estudios obtienen un diploma de "Profesor de Educación Física". A su vez, se establece una suerte de requisito ético, de principio deontológico de los docentes: "se exigirá de los Profesores de Educación Física, condiciones morales e intelectuales, de acuerdo con la importancia de esta enseñanza, y gozarán de una asignación mensual igual a la de los demás profesores" (ARGENTINA, 24 feb. 1905).

En definitiva, lo que el Plan produjo es una formalización de la disciplina a raíz de la conjunción de tres procesos: la legislación de su gestión, la definición tanto del nombre cuanto de su currícula y la precisión de los modos en que se instruye el oficio. Para cumplir con este último propósito establece una "episteme sintética", una reunión de los principales postulados de la pedagogía del "Sistema Argentino de Educación Física" con algunas de las características que la corporación militar promulgaba a través de la Escuela. Más aún, puede afirmarse que intentó ser una suerte de profundización en la uniformidad de los discursos. Esto es, ante la diversidad de maneras de llevar a cabo la profesionalización, la respuesta estatal consistió en la decisión de homogeneizar las prácticas a partir de uniformar sus criterios.

En otras palabras, puede afirmarse que intentó ser una suerte de sutura de las propuestas de ambos establecimientos. Sin embargo, los efectos de este proceso fueron contrarios a los pretendidos: la intención de reunir sus contenidos en una misma currícula, permitiendo su convivencia, resultó una oportunidad para que se distingan aún más, fomentando lo que a la postre constituye la disputa que diera nacimiento al campo de la formación superior en Educación Física. 
Ahora bien, los Cursos Normales, producto directo del Plan, son promovidos por el Consejo Nacional de Educación desde 1905 y están "destinados a los maestros empleados en las escuelas públicas de la ciudad de Buenos Aires”. Las novedades que presentaron fueron su carácter de permanentes y que se desarrollaron en paralelo al período lectivo. A su vez, por formar parte de la naciente burocracia educativa, fundamentalmente desde su cargo de Inspector de Educación Física entre 1904 a 1909, Romero Brest logró que se adoptara definitivamente el "Sistema Argentino" como oficial, a partir del cual cuestionó todo intento por militarizar la disciplina.

"Fúndase la Escuela Normal de Educación Física sobre la base del actual Curso Normal de Educación Física" (ARGENTINA, 15 mayo 1909). Con estas palabras se concreta la institucionalización definitiva de la disciplina, catalogada por Romero Brest como una revolución "de la más alta importancia técnica y política", teniendo por doble misión capacitar a los maestros que se encontraban dictando clases en la escuela primaria y "preparar verdaderos profesores de educación física" (1910, p. 400-401). Este hecho es refrendado el 9 de mayo de 1912 por el Ministro de Justicia e Instrucción Pública Juan Manuel Garro, con el cambio de denominación de la "Escuela Normal" por el de "Instituto Nacional Superior de Educación Física” (ARGENTINA, o9 mayo 1912).

En resumen, puede afirmarse que si el pasaje de los Cursos Normales a la "Escuela Normal de Educación Física" representa un avance relevante en términos de normalización de la asignatura - baste ver, como metáfora que opera, sus nombres -, la apertura del Instituto significa un paso decisivo hacia su definitiva normación. 5 Proceso que a su vez inaugura los dos vértices sobre los

\footnotetext{
5 En investigaciones anteriores (GALAK, 2012a) se explicaba cómo el nacimiento en Argentina de la formación profesional en Educación Física era el resultado de la relación dialéctica entre una serie de procesos de normalización y normación disciplinar. Resignificando el sentido esgrimido por Michel Foucault en "Seguridad, Territorio, Población" (2006), quien interpela la articulación entre las normas y lo que se establece como lo normal - y, por ende, lo anormal -, puede observarse en el caso analizado cómo se produce "un vínculo de procesos concomitantes que se retroalimentan, en donde la búsqueda de leyes que regulen su especificidad e inserción en el Sistema Educativo resulta paralela a la pretendida tarea de normalizar qué es ser un hombre, qué una mujer, qué raza para qué país, qué higiene, qué valores, qué virtudes" (GALAK, 2012a, p. 46). Esto es, de la relación dialéctica entre los procesos de normación y normalización
} 
cuales se apoya una de las propiedades constitutivas de la disciplina: a raíz de instalarse como organismo oficial, estatal y nacional para la formación de profesionales, y a partir de comenzar a construir discursos que surjan del seno mismo de la Educación Física (desde el "Sistema Argentino" pero también desde el fomento de las investigaciones en la materia), se empieza a producir la autonomía relativa del campo.

\section{EL NACIMIENTO DE LA LUCHA SIMBÓLICA: LA AUTORIZACIÓN OFICIAL EN 1909 A LOS EGRESADOS DE LA ESCUELA PARA QUE DICTEN CLASES EN EL SISTEMA EDUCATIVO}

Ante el ímpetu con que se instaura el Instituto como establecimiento oficial encargado de la formación de profesores en Educación Física, surge como contrapartida un renovado movimiento del seno de la corporación militar que busca refundar su rol en esa materia. Viraje que se origina a partir de romper con la tradicional lógica endogámica de la Escuela en pos de una política de exteriorización que interpele la educación pública. Como consecuencia se produce una incipiente disputa entre ambas instituciones que, desde comienzos de la década de 1910, configura el suelo de creencias comunes sobre el que se paran y los posicionamientos epistémicos que constituyen las corporaciones "cívico-pedagógica" y militarista" (GALAK, 2012a). Puede afirmarse que no era simplemente un intento por recuperar el espacio cedido al Instituto, sino que era, a su vez, un movimiento por dominar la escena nacional a través de la enseñanza de determinadas prácticas corporales con un fuerte componente moral.

Teniendo como base el panorama abierto a raíz de la implementación del Plan de Enseñanza y Educación Física Nacional que introduce y reglamenta, entre otras disposiciones, el tiro al blanco en la instrucción pública, en marzo de 1905

disciplinar se estableció qué sentidos sobre los sujetos, los cuerpos y la política se legitimaron en los inicios de la Educación Física argentina. 
se produce la adaptación de los Planes de Estudios de los Colegios Nacionales y Escuelas Normales a esas prescripciones, conformando así la puesta en práctica de ejercitaciones militares en la educación civil, poniendo de relieve la importancia de la cultura física a raíz de su sentido utilitarista (ARGENTINA, o6 mar. 1905). Precisamente esta conjunción entre la inclusión de prácticas castrenses en el ámbito civil y la significación de la cultura física como subsidiaria de la educación intelectual da nacimiento, desde el seno de la corporación militar, a un movimiento que reivindica la importancia de la Escuela como formadora de profesionales en la materia. Proceso que se sustenta en las palabras de Arsenio Thamier y que se materializa en 1909 con el nombramiento de Maestros de Gimnasia y Esgrima para que impartan clases en escuelas públicas.

Los discursos de Thamier son particularmente significativos por que exponen una crítica profunda al primer decenio de la Escuela, esbozándolas desde el interior de esta doctrina, abogando un cambio de dirección que implique un posicionamiento político distinto. Partiendo de los resultados de la ley de 1905, Thamier propuso una "reorganización física militar" que se justificara por "razones de salud y de higiene", "una orientación más perfecta que la que actualmente tiene esta rama de su instrucción”, ya que "desgraciadamente van transcurridos diez años desde que estos hábitos han sido implantado con cierta regularidad sin que haya sido variado fundamentalmente y con ventajas apreciables" (1910). En ese sentido, la puesta en vigencia del Plan refleja para Thamier un "lirismo" en el cual la Educación Física estaba inmersa y del cual debe salirse.

Si bien crítico de la Educación Física "militarista", entiende que hay que procurar "campos de acción mejor definidos", y ante la pregunta por "¿cuál es la gimnasia que corresponde al niño, al adolescente y al soldado?”, afirma que sólo se consiguen resultados provechosos "por medio del orden, la progresión y la disciplina" (THAMIER, 1905, p. 639-641), es decir a través de la pedagogía que trasmite la Escuela. Su búsqueda consiste entonces en suplir la "completa falta de racionalismo, de ideas prácticas y ventajosas al fin de esta educación" con que se 
forma a los prebostes, para implementar, en su lugar, una manera "científica y racional": "la educación física de nuestro ejército", dice Thamier, "reclama imperiosamente una renovación sustancial", puesto que "nuestro ejército necesita de cosas serias para su educación y no de recursos exhibicionistas para ocultar su falta material y científica de educación física (1910, p. 526).

Resulta interesante que para combatir el exhibicionismo empirista basa sus predicamentos en los mismos autores europeos que se utilizaban en el Instituto, sumándole algunos propios de la tradición de la Escuela como, por ejemplo, Baumann: la "Educación Física militarista", esgrime Thamier, debe sustentarse a su entender en una congregación de fisiólogos e higienistas - como Mosso, Lagrange, Tissié y Marey, quienes "han inspirado la organización científica en el terreno de la educación, de la higiene y de la terapéutica muscular" -, pedagogos - como Spencer - y

\footnotetext{
los valiosos capítulos que los más insignes psicólogos de nuestros tiempos Williams James, Ribot, Wündt, Sergi, han consagrado al rol del músculo y de sus sensaciones en la vida de la conciencia, sus aptitudes educables como órgano y como función, bajo las leyes de la evolución biológica y del hábito, y su acción educadora como plataforma de la energía personal (THAMIER, 1907, p. 164-165).
}

Es decir, el cambio de rumbo propuesto por Thamier se sustenta en una racionalidad moderna que es similar en su forma del cientificismo fisiológico de Romero Brest, pero distinguiéndose en su fondo, pues la Educación Física debe instruirse como una facultad instrumental: en sus discursos puede interpretarse que sirve para otra cosa (para la moralidad, la virilidad, la salud, la intelectualidad, etc.), lógica pragmática que se sostiene en el respeto al orden y la disciplina con que los alumnos deben desempeñarse, lo cuál refleja el rigor militar que impregna las clases.

En definitiva, procura una Educación Física militar que se argumente en postulados cientificistas (fisiologistas, psicológicos y pedagógicos), pero que sus 
clases estén orientadas según un doble criterio: transmitir disciplina y formar individuos útiles. Respecto a lo primero, Thamier entiende "por disciplina, la obediencia absoluta y rápida, el silencio, la atención fija en el que está mandando, la comprensión de las órdenes impartidas, la ejecución exacta en tiempo y precisión, el ascendiente que haya alcanzado el profesor sobre sus alumnos" (1907, p. 46). En tanto que la utilidad está dada por "renunciar a la fácil labor de ser frondoso y entregarnos a la difícil y poco brillante de ser prácticos” (Ibid., p. 164).

La introducción de los juegos al aire libre presenta un acercamiento epistémico con los postulados del "Sistema Argentino", en tanto que la característica de instrumental de los contenidos de sus currícula y la obediencia a un orden que los condiciona resulta un alejamiento de los mismos - baste ver, al respecto, los sugestivos nombres de juegos que Thamier proponía para que los futuros profesionales enseñasen: "Caza al tercero", "Toma del Fuerte”, “Todos firmes”, "Carrera de banderitas", "Los Prisioneros" y "Tú te equivocas” -. En ese movimiento puede interpretarse la búsqueda por parte de la Escuela de una (nueva) identidad que configure cómo formar profesionales en Educación Física. A su vez, ese cambio de posición provoca un viraje exogámico que tiene como resultado la disputa por los puestos de trabajo en el ámbito civil y como efecto los primeros debates directos con Romero Brest y demás pedagogos que transmitían el "Sistema Argentino".

Estos postulados que se desprenden de los discursos de Thamier son materializados en 1909 cuando el personal militar formado en la Escuela es autorizado a dictar clases en el ámbito civil. Si bien los Maestros de Gimnasia y Esgrima impartieron lecciones en los establecimientos públicos antes de esta fecha, lo que esta reglamentación genera es la configuración de una igualdad de posibilidades simbólicas y materiales frente a una misma profesión, creando con ello la disputa directa por los puestos de trabajo. Más precisamente, el 6 de marzo de 1909, el Ministerio de Guerra resuelve nombrar profesores de tiro y de gimnasia - según la especialidad del docente - en Colegios e Institutos de 
enseñanza secundaria en todo el país (CRISTIANI, 1967, p. 51-52). ${ }^{6}$ La singularidad de este proceso, que significa el pasaje de la formación de recursos para satisfacer la demanda interna del ejército hacia una búsqueda por diseminar sus docentes fuera de éste, puede verse patentemente en el renovado intento en el contexto de "afirmación de lo nacional" por el "espíritu del Centenario" (ROMERO, 1987, p. 65) de instalar "batallones escolares" (PINI; ECCHERI, 1910; ROMERO BREST, 1914; SARAVÍ RIVIERE, 1998).

\section{CONSIDERACIONES TRANSVERSALES}

Es precisamente el desenlace de los procesos de asimilación del personal castrense a la educación civil, sumado a la confrontación dialógica que produjo el intento de algunos miembros de la corporación militar de difundir su Educación Física mediante los "batallones escolares", lo que posibilita el nombramiento del Instituto como establecimiento oficial para la formación de profesores. Consecuentemente ello produce la disputa simbólica y material por los modos instruir el oficio, arrojando como resultado la emergencia del "campo de la profesionalización en Educación Física argentina”. En efecto, esa búsqueda por la identidad profesional y ese distinto posicionamiento respecto a los contenidos que debería enseñar la disciplina, con la derivada instauración en los discursos de una otredad constitutiva, inaugura un nuevo escenario que configura el oficio. De la mano de este proceso de distinción, y del vientre de cada una de estas posturas, surge la tensión entre los discursos cívico-pedagógicos y militaristas, los cuales disputan el nomos del campo - esto es, las luchas simbólicas por la posición dominante - y la potencialidad y potestad de gobernar el suelo de

\footnotetext{
${ }^{6}$ Cabe la siguiente digresión: mientras que en 1909 los prebostes podían dictar clases en las escuelas, recién tres décadas más tarde los docentes formados fuera del Ejército fueron autorizados para hacerlo en éste: a partir del 7 de diciembre de 1943, previos estudios complementarios de tres a seis meses, el Ministerio de Guerra decreta que "los profesores de Educación Física con título expedido por el Ministerio de Justicia e Instrucción Pública puedan ingresar, a su solicitud, al Cuerpo de Gimnasia y Esgrima del Ejército" (ARGENTINA, 28 dic. 1943).
} 
creencias comunes.

Como principales consideraciones puede afirmarse que mientras que la Educación Física nace a raíz de la disputa entre pedagogos y militaristas, la historia oficial muestra constantes intentos por homogeneizar los discursos y sentidos disciplinares que con diferentes argumentos pretendieron imponerse desde ángulos distintos, unificarlos de manera tal de establecer una manera única de llevar a cabo las prácticas. Lo cual produce que, como una cuestión que signa la Educación Física argentina, emerjan aquellas voces que postulen como un valor que la doctrina a seguir debe consistir en una postura ecléctica, que reúna, dentro de lo posible, lo mejor de disímiles corrientes y acepte la diferencia aún cuando sea contradicción. Esto es, siempre y cuando respete postulados científicos o pretendidamente cientificistas, parece habilitarse que cualquier discurso que refiera a la pedagogía sobre los cuerpos es contemplado, lo cual implica tornar el disvalor de la indefinición conceptual en una bandera positiva en la pretendida búsqueda de una identidad. Cualquier similitud con la actualidad no es pura coincidencia.

\section{REFERENCIAS}

AGÜERO, Abel, IGLESIAS, Silvia; VALLE MILANINO, Ana. Enrique Romero Brest y los inicios de la educación física escolar. Su tiempo, su vida, su pensamiento y su obra. Revista eä: Revista de Humanidades Médicas y Estudios Sociales de la Ciencia y la Tecnología, v. 1, n. 1, p. 1-38, 2009.

AISENSTEIN, Ángela. La educación física en el currículo moderno o la historia de la conformación de una matriz disciplinar (Argentina, 1880-1960). In: ROZENGARDT, Rodolfo (org.). Apuntes de historia para profesores de Educación Física. Buenos Aires: Miño y Dávila, 2006. p. 69-84.

AISENSTEIN, Ángela. La educación física en el currículo moderno o la historia de la conformación de una matriz disciplinar (Argentina, 1880-1960). In: ROZENGARDT, Rodolfo (org.). Apuntes de historia para profesores de Educación Física. Buenos Aires: Miño y Dávila, 2006. p. 69-84. 
AISENSTEIN, Ángela; SCHARAGRODSKY, Pablo. Tras las huellas de la educación física escolar argentina. Cuerpo, género y pedagogía. 18801950. Buenos Aires: Prometeo, 2006.

ARGENTINA. Boletín Oficial de la República Argentina, 06 mar. 1905. ARGENTINA. Boletín Oficial de la República Argentina, o9 mayo 1912. ARGENTINA. Boletín Oficial de la República Argentina, o9 oct. 1901. ARGENTINA. Boletín Oficial de la República Argentina, 15 mayo 1912. ARGENTINA. Boletín Oficial de la República Argentina, 19 abr. 1901. ARGENTINA. Boletín Oficial de la República Argentina, 24 feb. 1905. ARGENTINA. Boletín Oficial de la República Argentina, 28 dic. 1943. ARGENTINA. Escuela de Militar de Gimnasia y Esgrima. Revista del Club Militar, v. 1, n. 1, p. 130-134, 1900.

COMANDO EN JEFE DEL EJÉRCITO. Reseña histórica y orgánica del Ejército Argentino. Círculo Militar, v. 2, p. 635-636, 1971.

CRISTIANI, Roberto. Reseña histórica del cuerpo de Gimnasia y Esgrima del Ejército y su proyección en la vida nacional. Algunos aspectos de su evolución entre 1897-1960. Comando en Jefe del Ejército, v. 3, n. 3, 1967.

FOUCAULT, Michel. Seguridad, territorio, población. Buenos Aires: Fondo de Cultura Económica, 2006.

GALAK, Eduardo. Del dicho al hecho (y viceversa). El largo trecho de la construcción del campo de la formación profesional de la Educación Física en Argentina. Legalidades, legitimidades, discursos y prácticas en la institucionalización de su oficio entre finales del siglo XIX y el primer tercio del XX. 332 p. 2012. Tesis (Doctorado en Ciencias Sociales) - Universidad Nacional de La Plata, La Plata, 2012a.

GALAK, Eduardo. Del sintagma al oxímoron. La construcción del currículum y del oficio de Educación Física en la Argentina de fin de siècle XIX. Revista Educación Física y Deporte, v. 31, n. 1, p. 777-787, $2012 b$.

GALAK, Eduardo. Herbert Spencer y la pedagogía integralista. Influencias en los inicios de la Educación Física argentina. In: GALAK, Eduardo; VAREA, Valeria (org.). Cuerpo y Educación Física. Perspectivas latinoamericanas para pensar la educación de los cuerpos. Buenos Aires: Biblos, 2013. p. 45-66. 
GAYOL, Sandra; MADERO, Marta. Formas de historia cultural. Buenos Aires: Prometeo, 2007.

PINI, Eugenio; ECCHERI, Herminio. Batallones escolares de la República Argentina. Buenos Aires: Sociedad Sportiva Argentina, 1910.

PIZZURNO, Pablo. El Instituto Nacional Superior de Educación Física. El Monitor de la Educación Común, v. 33, n. 504, p. 399-414, 1914.

PIZZURNO, Pablo. Enseñanza secundaria y normal. Informe correspondiente a 1901-1902. Buenos Aires: Taller Tipográfico de la Penitenciaria Nacional, 1902.

POURTEAU, Salustiano. Breves reflexiones sobre la educación física. Buenos Aires: Imprenta Helvetia, 1897.

ROMERO BREST, Ernesto. Cursos Normales de Educación Física (sus resultados). Buenos Aires: Librería y Casa Editora de Nicolás Marana, 1903.

ROMERO BREST, Ernesto. El sentido espiritual de la educación física. Buenos Aires: Librería del Colegio, 1938.

ROMERO BREST, Ernesto. Evolución de la Educación Física en la Escuela Argentina. Censo General de Educación. Buenos Aires: Talleres de Publicaciones de la Oficina Meteorológica Argentina, 1910. p. 363-416.

ROMERO BREST, Ernesto. Los batallones escolares. Orígenes, condiciones científicas, defectos. Buenos Aires: Talleres Gráficos de la Penitenciaria Nacional, 1914.

ROMERO BREST, Ernesto. Pedagogía de la educación física (1905).

Buenos Aires: Librería del Colegio, 1933.

ROMERO, José Luis. El desarrollo de las ideas en la sociedad argentina del siglo XX. Buenos Aires: Nuevo País, 1987.

SARAVÍ RIVIERE, Jorge. Aportes para una historia de la educación física. 1900 a 1945. Buenos Aires: Agencia Periodística Cid, 1998.

SARAVÍ RIVIERE, Jorge. Historia de la educación física argentina. Siglo XIX (notas para su elaboración). Buenos Aires: Impresiones Agencia Periodística Cid, 1985.

SCHARAGRODSKY, Pablo. Cuerpo, género y poder en la escuela. El caso de la Educación Física escolar Argentina (1880-1930). Revista Ethos Educativo, v. 33-34, p. 39-67, 2005. 
SCHARAGRODSKY, Pablo. La invención del "homo gymnasticus". Fragmentos históricos sobre la educación de los cuerpos en movimiento en Occidente. Buenos Aires: Prometeo, 2011.

\section{SCHARAGRODSKY, Pablo. Miradas médicas sobre la cultura física en \\ Argentina: (1880-1970). Buenos Aires: Prometeo, 2014.}

THAMIER, Arsenio. Educación Física militar. Revista de la Educación

Física, v. 2, n. 17-18, p. 513-533, 1910.

THAMIER, Arsenio. Educación física. Guía teórico-práctica del profesor. La Plata: Talleres Gráficos Solá y Franco, 1907.

THAMIER, Arsenio. Educación Física. Reflexiones. Revista de Educación de la Provincia de Buenos Aires, v. 5, n. 7, p. 639-641, 1905.

EDUARDO LAUTARO GALAK es profesor en Educación Física, magíster en Educación Corporal y doctor en Ciencias Sociales por la Universidad Nacional de La Plata (UNLP, Argentina), con post-doctorado en Educação, Conhecimento e Integração Social (Universidade Federal de Minas Gerais UFMG, Brasil). En la actualidad es Investigador Adjunto del Consejo Nacional de Investigaciones Científicas y Técnicas (Conicet), Universidad Nacional de La Plata (UNLP) / Instituto de Investigaciones en Humanidades y Ciencias Sociales (IdIHCS), en Argentina. Ejerce la docencia actuando en grado y posgrados. Es autor del libro Educar los cuerpos al servicio de la política. Cultura física, higienismo, raza y eugenesia en Argentina y Brasil (2016) y compilador de Cuerpo y Educación Física. Perspectivas latinoamericanas para pensar la educación de los cuerpos (2013) y Cuerpo, Educación, Política: tensiones epistémicas, históricas y prácticas (2015), así también como de diversos artículos y capítulos de libro en los que trabaja la relación entre educación del cuerpo y (re)producción política, principalmente a través de analizar genealógicamente discursos referidos a la formación profesional, a la estética, al cine, al cientificismo, a la salud e higiene públicas y al mejoramiento de la raza.

E-mail: eduardogalak@gmail.com

(1) http://orcid.org/0000-0002-0684-121X

Recebido em: 15 de janeiro de 2018

Aprovado em: 21 de dezembro de 2018 